\title{
Delineating Latino Student's Reading Strategies
}

\author{
Mauricio Cataldo López*
}

\section{Resumen:}

El artículo da a conocer un estudio a escala menor llevado a cabo para investigar e identificar las estrategias de aprendizaje utilizadas por un estudiante para mejorar su conocimiento del Ingles como segunda lengua junto con la comprensión lectora. El estudio involucro a un aprendiz de un país de habla hispana, ejecutando una tarea de lectura (reading task) y sometiéndose a una entrevista posterior a la tarea. El análisis de su desempeño evidencio un alto nivel en el uso de estrategias metacognitivas que se correlacionan con su experticia lingüística. A través de los resultados obtenidos, esperamos contribuir a los continuos esfuerzos hechos por profesores de ingles (EFL) para realzar las habilidades del procesamiento de la lengua Inglesa en los estudiantes, mediante un enfoque metodológico que conlleva una orientación más pedagógica para la enseñanza de las estrategias de aprendizaje y que se ajusta a las características de los alumnos.

Palabras Clave: Estrategias de aprendizaje, habilidad lectora, estilos de aprendizaje, instrucción de estrategias de aprendizaje

\section{Abstract:}

This paper reports on a small-scale study carried out to investigate and identify the learning strategies used by a student to improve second language learning along with reading comprehension. The study comprised a learner from a Spanish -speaking background performing a reading task and undertaking a post-task interview. Analysis of the performance evidenced a high level of metacognitive strategies use that correlate with the learner's language proficiency. Results may contribute to the growing efforts made by EFL teachers to enhance students' language processing skills by embracing a teaching approach that adopts a pedagogical stance towards learning strategy instruction and meets learners' characteristics.

Key Words: Learning Strategies, reading proficiency, learning styles, learning strategy instruction

* Profesor de Inglés. Universidad Católica Silva Henríquez. mcataldo@ucsh.cl 


\section{Background to the Study}

The growing influence and role of language learning strategy instruction in helping language learners to become more efficient and effective could be best synthesized in Oxford's words as "the steps taken by students to enhance their own learning" (1990 p. 1). However, such important 'tools' for language learning are still unclear for many practitioners who lack training in the use of these strategies (Wenden, 1995).

Hence, this study explores the use of language learning strategies as an important aspect in the success of an EFL learner in any language learning task. The main objective behind this study is to identify the language learning strategy choice and to address the issue of fostering language learning strategies within the teaching discipline. Therefore, the questions leading this study refer to what language learning strategies does an intermediate EFL learner from a Spanish-speaking background make use of? Moreover, to what extent do the learner's language proficiency and academic background influence the learner's learning strategies preference?

\section{Reading Proficiency and Strategy Use}

Concerning second language reading proficiency, the early body of reading research focused on the product-oriented perspective. However, the advent and influx of cognitive psychology has exerted a profound influence towards a more process-oriented stance (Anderson, 1991). Knowledge about the process, not just the score attained, is required to truly address the needs of students and help them become aware of the role of reading as an indispensable tool, necessary for accomplishing life's tasks as well. 
With this scenario in mind, the particular aim of reading research has been the study of reading strategies used by learners in different contexts. This has been the pivotal concern of Block's study (1986) who describes two distinctive groups: Hispanic and Chinese ESL learners- in relation to two different pattern of reading strategy use. She defines one subgroup as 'integrators' who focus on understanding the author's ideas without attaching any affective tie to the text, and checking their comprehension effectively. On the other hand, 'nonintegrators' appear to personally associate with the text, attending to their own feelings and developing a personal and customized version of the text. Therefore, one of her major conclusions approaches the pattern of use adopted by the 'integrators' which resulted in an improved reading performance in a formal test. In line with Block's findings, Anderson (1991) shows a similar scenario where three participants with differing level of proficiency tend to make use of the same strategies. The latter seems to demonstrate that "strategic reading is not a matter of knowing what strategy to use, but also the reader must know how to use a strategy successfully and orchestrate its use with others" (p.469).

However, O'Malley et al. (1985a), in a study of high school ESL Hispanic students, found the opposite, advance learners showed superiority over beginners in terms of metacognitive strategies use. More evidence supporting this claim is given by Politzer and McGroarty (1985), Ehrman (1990 cited in Ellis, 1994) who confirm that students with previous academic studies tend to use more strategies and with more frequency than untrained learners. As a result, there is plenty of evidence reinforcing the assumption that the learner's background makes a difference when it comes to learning strategies management.

\section{Metacognitive Strategies and their Effect on L2 Development}

Of increasing interest for reading research has been the focus on metacognitive knowledge -what learners know about their own learning process, the task of reading and reading strategies. Carrell's (1989) pioneering study, involving ESL Hispanic students and native speakers of English studying Spanish, reveals the way efficient readers interact with written text and how these strategies are related to their metacognitive awareness-how to adjust one's cognitive activity to improve learning-and comprehension. Her findings among ESL Hispanic learners show that effective readers, coincidentally those having one level of proficiency over the rest, conceive 'global' top-down strategies (focusing on background knowledge, text-gist and textual organization) as supportive steps to rea- 
ding performance. In contrast, lower level ESL learners tend to rely more on 'local' bottom-up strategies (those having to do with sound-letter, word meaning, syntax and text details), thus validating the use of these sentence-bound strategies as they move toward reading proficiency. Similar evidence was found by O'Malley et al (1985b), suggesting that advance learner can attend to other aspects of learning that mere input, for example metacognitive control. Along with this concern for strategy use, it is necessary to acknowledge the role of those metacognitive factors that come into play in the monitoring of the reading activity. As Carell (1989) concludes "the first aspect of metacognition is the reader's conceptualization of the reading process: how the reader conceptualizes what s/he is doing in reading" (p.122).

\section{Cultural Variables Influencing Learning Strategy Choice}

Unlike the inherent traits of our personality that may affect language learning development the influence of cultural background appears to be the most relevant factor determining the language learning strategy choice. The seminal study on cross-cultural use of language learning strategies made by Oxford (1996) shed light on the prominence of cultural issues for language teaching. Therefore, culture not only provides a framework within which our lives develop but also shapes our values, beliefs and predominantly general learning styles that play a vital role in the learning process. Liyanage (2004) shows a similar insight in his study, although he stresses the need for sociocultural context-focused strategy instruction rather than cross-cultural comparisons. With regards to Spanish-speaking ESL learners, Griggs and Dunn (1996) affirm that Hispanic ethnic background encourages global and field dependent learning style that often manifest in the learners' adoption of particular strategies such as predicting, inferring, working with others and avoiding details.

Nevertheless, the influence of culture on strategy choice appears to be held in some dispute by some researchers. Block (1996) supports the contention found in her study that cultural background did not account for the similar patterns of strategy use shared by two disparate, albeit limited in number, groups of ESL learners from Chinese and Hispanic ethnic backgrounds (p. 484).

This review of the literature has served to reveal aspects related to language learning strategy. Furthermore, all the factors shown in this evaluation strongly influence language learners' preference of strategies. Therefore, the basic rationale of this analysis has been the identification 
of appropriate learning strategies that enable learners to assume responsibility for their own learning by enhancing learner autonomy and self-direction.

\section{Findings and Interpretations}

The data gathered for this study were predominantly quantitative in nature. The specific quantitative analysis focused on the occurrences of learning strategies throughout the reading task, according to the taxonomy provided by O'Malley et al. (1985b).

Table \#1 Reading strategies used at the pre, during and post stages of the task

\begin{tabular}{|l|c|c|}
\hline Strategy Type & Occurrences & Percentage \\
\hline Raw Total: Number of Strategies Used & 43 & $(100 \%)$ \\
Metacognitive Strategies & 24 & $(\mathbf{5 5 . 8 1 \% )}$ \\
- Advance Organization & 8 & $(18.60 \%)$ \\
- Organizational Planning & 1 & $(2.32 \%)$ \\
- Directed Attention & 2 & $(4.65 \%)$ \\
- Selective Attention & 4 & $(9.30 \%)$ \\
- Self-Monitoring & 5 & $(11.62 \%)$ \\
- Self-Evaluation & 3 & $(6.97 \%)$ \\
- Self-Management & 1 & $(2.32 \%)$ \\
& 17 & \\
Cognitive Strategies & & $(\mathbf{3 9 . 5 3 \% )}$ \\
- Rehearsal & 2 & $(4.65 \%)$ \\
- Inferencing & 3 & $(6.97 \%)$ \\
- Resourcing & 3 & $(6.97 \%)$ \\
- Grouping & 1 & $(2.32 \%)$ \\
- Translation & 1 & $(2.32 \%)$ \\
- Deduction/Induction & 1 & $(2.32 \%)$ \\
- Elaboration & 3 & $(6.97 \%)$ \\
- Contextualization & 3 & $(6.97 \%)$ \\
Social Affective & $\mathbf{2}$ & $(4.66 \%)$ \\
- Questioning for Clarification & & \\
\hline
\end{tabular}

Figure \# 1 illustrates the percentage of each type of strategies. The most statistically relevant difference was between metacognitive and cognitive strategies. At naked eye, another significant difference was found for the low use of social affective throughout the task.

From the results obtained in Table\# 1 , it clearly appears that both metacognitive and cognitive strategies, which comprised $95.34 \%$, became the most appropriate 'tactics' that the EFL learner relied on when reading. Hence, the other two steps of the presentation of the results tackle these two strategies. 
Figure \#: 1Major Metacognitive Learning Strategy Uses by an Intermediate EFL Learner

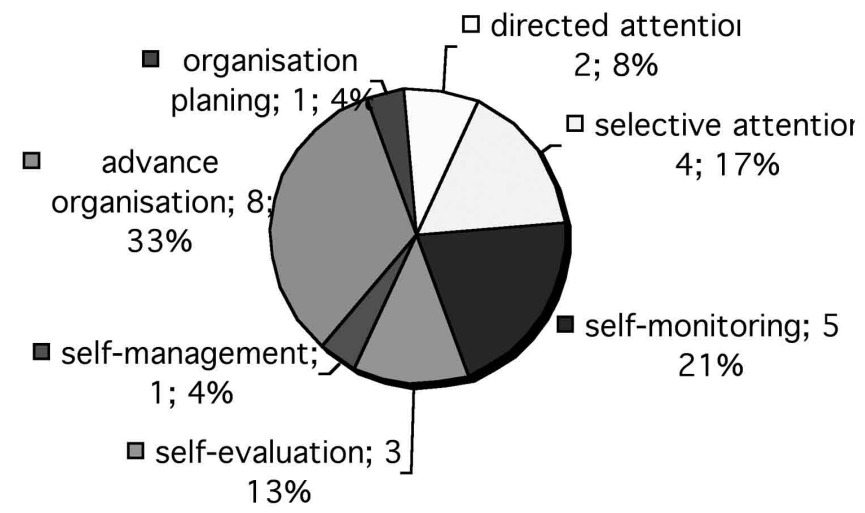

Figure \# 2: Principal Cognitive Strategy Uses by an Intermediate EFL Learner

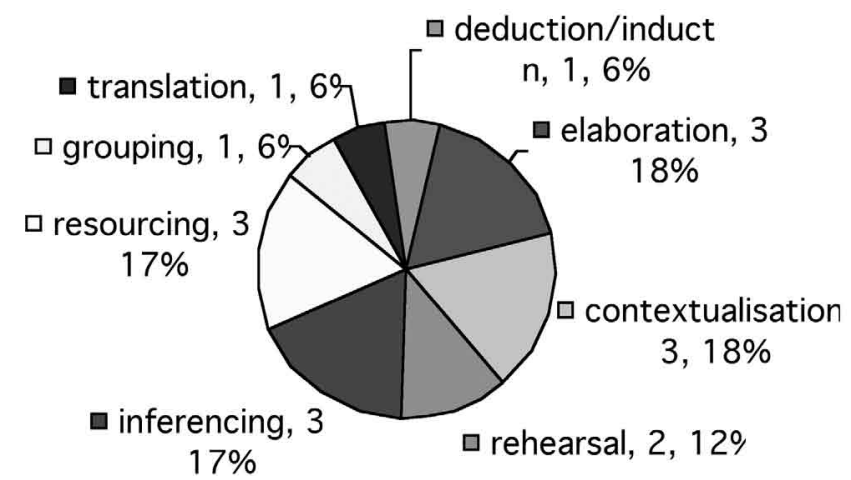

Figures \#1 and \#2 highlight those metacognitive strategies used in greater proportion for this reading task. Significant differences favored metacognition thinking for the following strategies: advance organization being the most frequently used throughout the task, self-monitoring and selective attention respectively, whereas metacognitive strategies saliently supported the manipulation of information, and examples are differencing, resorting, elaboration and contextualization.

There are a number of interpretations of the findings presented above, to begin to deal with those, the first plausible explanation is that metacognitive strategies positively affect the language learning proficiency. The reason behind this came out from O'Malley et al. and Carrell's claims, shown in the literature review, that strongly support the idea that advanced students incubate metacognitive strategies in a larger number than lower-level students. An additional finding of interest was the overall proportion of use of the self-monitoring strategy displayed by the 
ESL leaner, frequently reported expressions like 'If I ask myself and don't have the answer for every question'(appendix \# 1 line 125) implies the development of metalinguistic awareness. A notion expressed by Carrell (1989) and that is replicated in this study by the ESL learner from the same ethnic background as the ones who took place in her study. The ability of the ESL learner to continually check his comprehension independently from concentrating on the information reflects a high level of strategic reading proficiency and perceivable autonomy.

In contrast with the point made above, it is Anderson's claim (1991) that correlates success in academic reading tasks with factors other than language proficiency such as learning style, motivation and so on, a notion that at first sight could be arguable. However, this study appears to favor Anderson's assertion. Some reported comments made by the EFL learner and further analyses during the review of the transcript seemed to involve other components, specifically aspects of the learner's background, interest on the topic of the passage and motivation, apart from only reading strategies. Samples obtained from the transcripts (appendix \# 1) as 'I'll be very interested and I have curiosity about this' and 'I was thinking the topic was about university studies it will be easy for me' demonstrate a pre-determined leaning to tackle the text. Such readymade perspective, thus, may explain the varied and active use of learning strategies and further accomplishment of the learning challenge.

Another plausible explanation for his successful reading performance refers to the use of language learning styles that may have triggered by his highly intrinsic motivation. As far as Hispanic learners' learning style is concerned, studies have shown a tendency for Hispanic students to reflect a more global thinking. Hence, traces of the ESL learner's approach were largely reported during the interview and categorized as learning strategies. Examples of these are found in the following 'I tried to guess from the context' (appendix \# 1 line 123) or 'the first part the introduction because I will have a picture about the ...essay' (appendix \# 1 line 17). Therefore, the connection of global thinkers with 'top-down' strategies that build on drawing inferences and seeing the whole fit with the description of strategic readers found under the label of 'integrators'.

Among the many model of proficient readers describe in the literature, one group who stand out are the so-called 'integrators' (Block, 1986). By 'integrators' Block refers to active readers who are able to integrate information and monitor their understanding of the reading comprehension. The EFL participant in the study holds great potential to be labeled as 'integrator'. He described his reading approach as follows 'I tried to find the relation between the body and the introduction'(appendix \#1, line 17) or 'l look at the meaning and try to get a relationship between meaning 
and pronunciation'(appendix \#1, line 107). In addition, his operations and strategies described in the retrospective report reveal to some extent a certain attachment to the topic, for example the expression 'the student chose six subjects and I was thinking about my university life' (appendix \#1, line14) demonstrates that his strategy to make sense of the text focuses on ideas or concepts that carry an affective load.

Finally, although many of the features describe in this section hold potential for language learning, aspects of the learner's psychological domain were not systematically observed thus, they are regarded rather as assumptions in the present study.

\section{Implications of This Study for EFL Classrooms}

As suggested by this study, language learning strategies are important determinants of learners' success in traditional language classrooms. Thus, language teachers should become aware of its relevance and encourage learners to have the chance to gain a deeper understanding of their learning process. In doing so, it appears that the adoption of a task-based approach (TBA) sits well with the idea of fostering the strategic and simultaneous application of knowledge and action , a view that, in language teaching enhances the refinement of language processing skills (Birch, 1998). In line with this idea, it is Foley's claim (1991) that TBA bridges learners' current competence in their L1 and the future mastery and use of the L2 by giving learners "the opportunity for joint decision making in the interactive process of learning" (p.71)

Another clear inference from this work would be the adoption of contemporary assumptions of the language learning/teaching process that foreground the belief that attention to the learner should be central to all aspects of language teaching, in strict contrast with old views where all teaching practice was concentrated on decisions based on teachers' priorities. Such contemporary perspective has consolidated a learner-centred approach. An educational philosophy that emphasizes a pedagogically negotiated model of planning and instruction which is arrived at by the collaborative effort between teachers and learners. (Nunan, 1988).

Therefore, it is the ultimate aim of teachers to seek for the best ways to foster language learning strategies, bearing in mind that they must accommodate learners' different learning styles as well as idiosyncratic and cultural features within an optimal language learning environment. 


\section{Conclusion}

In summary, this study attempts to answer two research questions: What language learning strategies does an intermediate EFL learner from a Spanish-speaking background make use of? and To what extent do the learner's language proficiency and academic background influence the learner's learning strategies preference?

The first question was largely displayed in the table \# 1 and figures \#1\&2 and it refers to metacognitive and cognitive strategies. The conclusions arrived at replicate previous results found in other studies. Particularly, concerning the importance of metacognitive strategies as regulators of learners' progress in language learning. Evidence from this work suggests that the EFL Hispanic learner possesses a variety of metacognitive strategies when dealing with reading comprehension tasks. The strategies of advance planning and selective attention were notable in this regard. Consequently, evidence of the development of his metacognition knowledge was the major finding of this study.

On the other hand, the use of cognitive strategies accounts for the ability of the ESL learner to manipulate specific input presented in the passage while reading. These operative strategies were more prevalent on the 'integrator' reader model. Hence, inferencing and elaboration become the manifestations of his global thinking. This particular learning style that appears to largely influence the learner's strategy choice. This latter assumption comes from matching the learner's reports and descriptive profiles found in the literature with regards to 'global thinkers'. Therefore, it should be noted that the answer for the second question is not clearly met in this study and requires further research.

One final comment regarding the rationale of this study, it was the intention of this research to identify the most useful language learning strategies with the ultimate aim of helping learners move beyond the text and become more autonomous in their learning development.

\section{References}

Anderson, N. (1991)

Birch, G. (1998)
"Individual Differences in Strategy Use in Second Language Reading and Testing". The Modern Language Journal, 75, (4), 460-472.

"The Reflective Practice Method". QATESOL Newsletter. 2, 6-13. 
Delineating latino student's reading strategies /

Mauricio Cataldo López

Block, E. (1986)

"The Comprehension Strategies of Second Language Readers". TESOL Quarterly, 20, 463-494.

Carrell, P. L. (1989)

"Metacognitive Awareness and Second Language Reading". The Modern Language Journal, 73, 121134.

Chamot, A. (1987)

"The Learning Strategies of ESL Students". In Wenden, A. \& Rubin, J. (eds.). Learner Strategies in Language Learning. London: Prentice Hall International, pp. 71-83.

Ellis, R. (1994)

"The Study of Second Language Acquisition". Oxford: Oxford University Press.

Foley, J. (1991)

"A Psycholinguistic Framework for Task-based Approaches to Language Teaching". Applied Linguistics, 12, (1), 62-73.

Griggs, S. and Dunn, R. (1996)

Hispanic-American Students and Learning Style. Eric Digest. (ERIC Document Reproduction Service No. 393607). Retrieved May 22, 2006, from $E^{\prime}$ subscribe/ERIC Reproduction Service database.

Liyanage, I. (2004)

An Exploration of Language Learning Strategies and Learner Variables of Sri Lankan Learners of English as a Second Language with Special Reference to Their Personality Types. Unpublished Doctor of Philosophy Thesis, Griffith University.

Nunan, D. (1988)

The Learner-Centred Curriculum: A study in Second Language Teaching. Cambridge: Cambridge University Press.

O'Malley, J. M., Russo, R. P., Stewner-Manzanares, G. and Kupper, G. (1985a) "Learning Strategies used by Beginners and Intermediate ESL Learners". Language Learning, $35,21-46$.

O'Malley, J. M., Russo,R. P., Stewner-Manzanares, G. and Kupper, G. (1985b) "Learning Strategy Applications with Students of English as Second Language". TESOL Quarterly, 19, (3).

Oxford, R. (1996)

"Why is Culture Important for Language Learning Strategies?" In R. L. Oxford (Ed.), Language Learning Strategies around the World: Cross Cultural Perspectives (pp. ix-xv). Honolulu: Second Language Teaching \& Curriculum Center University of Hawai'i at M'anoa. 
Politzer, R. and McGroarty, M. (1985)

"An Exploratory Study of Learning Behaviours and Their Relationships to Gains in Linguistic and Communicative Competence". TESOL Quarterly, 19, 103-123.

Wenden, A. (1995)

"Learner Training in Context: A Knowledge-based Approach to Promoting Autonomy". System, 23 (2), 183-194

\section{Appendix \# 1}

Post-interview on task completion (Transcription)

\section{I: Interviewer}

P: Participant

\section{Questions related to the planning and preparation stage.}

1) I: What did you think about the first time I told you about this activity?

2) P: I will be very interested and I have curiosity about this

3) I:What were you curious about, specifically? for example the purpose or the relevance for your studies,

4) P: No I don't think so. I was curiosity about the curiosity about the strategies or things can I find new for me, new information

5) I: How did you prepare for this activity? Did you do anything?

6) P: Nothing

7) I: What did you do first when you had the text in your hands?

8) P:I read the title and no more that was my first step

9) I: Did you plan or did you design a plan to attack the text? Did you decide to make a plan...?

10) P: No , no I didn't

11)I: Did you look at the pictures, something else?

12) P: No, I just focused on the title

13) I: After that, what were you thinking when you're looking at the title?

14) P: I was thinking the topic was about university studies it will be easy for me

15) I: So you started relating that to your previous experiences

16) I: After you did that, what did you do before starting the reading ? you look at the title and then.... 
17) P: The first part, the introduction.... for me it is very important the introduction.... Because I will have a picture about the... all the essay

18) I: Ok that was your plan, so after reading the title you focused on the subheadings and introduction

19) I: After reading that, did you decide any plan any method to read the rest?

20) P: Yes I scan/ skimming

21) I: You mean the text

22) I: How did you do that?

23) P: Just one thing probably, to find things they are related with the introduction

24) I: You were looking for clues

25) P: Related words with the introduction

26) I: So you were looking at the whole text

27) P: Yes but in order

28) I: Apart from that, what else did you look at.. did you look at pictures, familiar words...?

29) $P$ Just related words

30) I: So, what helps you understand the whole meaning, the overall meaning of the passage?

31) P No, I think the introduction because the other part is just the development

32) I: Details...

33) $P$ details and complement

34) I: So you were focused on the introduction the get the main idea.

35) I: Did you think of any special tricks to help you identify new words?

36) I: For example, when you came across unfamiliar words.

37) I: Did you have any other tricks to understand the meaning?

38) P: Yes, I read before the word and after the word

39) I: So you looked at the context where the word is embedded

40) P: Yes, the context, yes.

41) I: That is the plan you always use, ok.

42) I: Did you consider any personal reward for this task?

43) P: What is reward?

44) I: For example in my case when I finish an assignment I get a book or go to the movies its like a personal thing you get when you did something important

45) I: No, in my case. 


\section{Questions about the reading process}

46) I: Can you tell me how did you do this task? How did you do the reading?

47) $\mathrm{P}$ : What is my approach?

48) $\mathrm{T}$ : So in the process did you pay more attention to the general idea, sentences and so on?

49) P: The thing is .... Paragraphs they have more information or that

50) I: Did you go paragraph by paragraph

51) P: But I tried to be focus in some...

52) I: Paragraphs

53) P: No, no. because paragraphs have just details and examples

54) I: O.k. as you were reading, in the process, what helps you to understand the general, the overall meaning of the text?

55) P: The same the introduction for me is very important if I don't understand the introduction I can't ...?

56) I: You can't go any forward

57) I: What did you do when you didn't understand the meaning of a particular word?

58) P: Oh just, look the context or the...

59) I: So what did you do to help yourself the overall meaning?

60) P: Put together the overall... and that can give me an idea.

61) I: Did you check your comprehension while you were reading?

62) P No...I don't think so.

63) I: You didn't check yourself if you understood the main idea

64) I: Did you think of using any help, dictionaries, for example?

65) P: I don't like to use dictionaries, but sometimes just only for particular words, when I finish just to review something like that but no more.

66) I: So you are not a dictionary dependant

67) I: Did you consider or think of using translation. Did you translate any sentence?

68) P: Yes, sometimes I have to translate to Spanish first, mentally and then mostly when Is like when these... ( here he tries to remember)like this international school and la... la... la... several words together

69) I: So you have to reorder them in your mother tongue. How did you do that?

70) P: That's is hard for me because I tried to read firstly the noun and then the adjectives like in Spanish

71) I: you start from backwards 
72) P: yeah, to get the meaning the whole meaning but sometimes I got lost something like that

73) I: Did you use previous knowledge to understand the overall meaning?

74) P: Yes, I think so because for example this article is about studies, universities but it is about banking, it is a bit difficult

75) I: Not related to your previous experiences and did you think of writing anything on the paper? or take notes?

76) P: It's not useful for me

77) I: You don't use that. Ok. Did you apply any rule to understand the language, for example you were thinking about present continuous, subject -verb or something else.

78) P:I don't use that because I lost time thinking about that grammar and so and I do that after the reading so I see grammar interesting things but for example after that I use dictionaries or I look for interesting structures grammar something like that

79) I: What did you put more emphasis as you were reading?

80) P: I think I tried to find the relation between a body of the text and the introduction so which phrases are giving me a or developing the introduction. no just examples the whole meaning about the topic and the introduction

81) I: How did you connect new information with previous experiences, previous knowledge?

82) P: Probably is like in this paragraph the student choose six subjects so I was thinking about my university experience, ten subjects. Its like a comparison with those students.

83) I: How did you relate to this passage?

84) P: Its like a comparison with those students. I tried to think about my life in the university and my life then.

85) T: As you were reading I noticed you talk to yourself in silence

86) I: Did you practice any pronunciation of any word in your mind?

87) P: Yes, for example when I don't remember some words.

88) I: What were you thinking at that moment?

89) P: I was trying to see if the sound is right or wrong

90) I: How does it help?

91) P: If I don't remember the pronunciation I tried to repeat the word many times

92) I: What did you do if this tactic does not work?

93) P: I use the dictionary to see the correct pronunciation

94) I: You mean, you check the phonetic transcription. 
95) I: Do you use that method with familiar words or unfamiliar words?

96) P: With both to remember and because I'm interested to know the new pronunciation.

97) P: But if the dictionary does not have transcription

98) I: What did you do?

99) P: Then I tried to guess the right pronunciation

100) I: So you were rehearsing in silence

101) I: How did it help to repeat the pronunciation? Is it helpful for you?

102) P: Yes, I think in this case is good but it's not enough

103) I: you say it is not enough. What else do you need?

104) I: Do you ask another classmate or the teacher directly?

105) P: directly, I ask to the teacher because I trust in his knowledge not in the others

106) I: what else did you use the dictionary for? For example when you look into the pronunciation that word, did you look at the meaning of the word?

107) P: Yes at the same time .look at the meaning and tried to get a relationship between meaning and pronunciation

108) I: You tried to imagine a relationship between those two things

109) P: Yea, to get relation a picture, a whole picture about meaning and pronunciation

110) I: What did you do to remember new words?

111) P: it's difficult but the best thing for me is... a examples with examples

112) I: Did you make new sentences?

113) P: Yes, use that word in....

114) I: In a different context?

115) P:Yes, different context into a phrase, paragraph something like that.

116) I: Have you ever tried to do any representation of a new word found in the text? any movement or sound related to it?

117) P: A representation....(he thinks about this word) yes, a picture with a context with examples is more useful for me because I can use it in a normal situation because I have the picture and I tried to say to have a good pronunciation not just the meaning.

118) I: Did you try to learn some new words by heart? by memory?

119) P: Probably some words I can do I can remember those words but is not useful.

I can't remember... my memory is difficult for me. 
120) I: Did you try to guess unfamiliar words?

121) P: Yes

122) I: So what did you do?

123) $\mathrm{P}$ : I tried to guess from the context can give me an idea.

124) T: How did you check your comprehension of the passage during the reading?

125) P: If I can have a relation between the body and the introduction but If I asked me myself and I don't have the answer for every question so I think I don't have good comprehension on that text I got lost

126) I: And did you go back to the text again

127) P: Yes

128) I: to get a better understanding

\section{Questioning pertaining to the completion/reflective stage}

129) I: So what was the first thing you did after reading the passage?

130) P: The first thing was to look at the questions because if I can give an answer for these ( pointing to the comprehension questions) very quickly that is because I understood. But if I can't so something is wrong.

131) I: So, what would you do in that case, you go back to the text again?

132) P: Yeah, to the text.

133) I: What did you do that helped you to answer the questions?

134) P:I think the first thing.... Is because I remembered that what could be the answer into the text. So the first question I think this is at the beginning of the text. For me that is a sign that I understand the text. Because I remember the... sequence.

135) I: So did you read the questions before reading the whole passage?

136) P: No, I don't like do that

137) I: How will you remember the words encountered in the text later?

138) P: Examples, I make sentences

139) I: After answering the comprehension questions, what did you do to check the main idea of the text?

140) P: I look if I have a good idea about the text, and if I don't have doubts about the answers

141) I: So if you are completely sure and you feel satisfied and that's it.

142) I: Finally, Can you describe your overall approach to reading in English?

143) P: I think for me the title, the first step is the title, the introduction and then is just find... 
144) T: Did you go very quickly or you go sentence by sentence?

145) P: I tried to have a good ..... I don't know a ...

146) I: A good reading pace

147) $P$ : Yes, because just is a sample something for me is more important the relation between the context and the beginning, the title an the introduction.

148) I: So, do you think there is any difference between reading in English and reading in Spanish?

148) P: It is not so different, I think it's very similar.

149) I: Do you use the same approach in other instances in your life, for instance at work, home, in your previous studies or current studies?

150) P: I think yes, I try to apply this approach in my life. In my current studies yes when I'm reading a newspaper, a book, an article something like that to use the same thing with those texts. 